\title{
Trifunctional Purine Biosynthetic Protein Adenosine-3
}

National Cancer Institute

\section{Source}

National Cancer Institute. Trifunctional Purine Biosynthetic Protein Adenosine-3. NCI

Thesaurus. Code C128850.

Trifunctional purine biosynthetic protein adenosine-3 (1010 aa, 108 kDa) is encoded by the human GART gene. This protein is involved in the de novo biosynthesis of purine nucleotides. 